Geophysics

\title{
Life, geology and snowball Earth
}

A ccording to the 'snowball Earth' hypothesis, a series of global glaciations occurred 750-580 million years ago, each lasting for millions of years and ending in a scorching heat caused by an extreme enrichment of atmospheric greenhouse gases. Hyde et al. ${ }^{1}$ have used climate models to simulate this global glaciation, finding in one case an alternative climate scenario in which a partially frozen Earth has ice-free oceans equatorward of $25^{\circ}$ latitude. We do not believe that this 'slushball' Earth is consistent with the most striking geological and palaeomagnetic observations explained by the snowball Earth hypothesis.

Palaeomagnetic and geological data from Neoproterozoic glacial deposits indicate that glaciations were long-lived (lasting for millions of years $)^{2,3}$ and locally associated with iron formations. The glacial deposits are covered by extraordinary sequences of carbonate sediments called 'cap' carbonates, which have unusual textures and low $\delta^{13} \mathrm{C}$ values. The snowball Earth hypothesis can explain all these observations ${ }^{3}$, whereas a semifrozen (slushball) Earth does not.

In the snowball Earth hypothesis, a runaway ice-albedo feedback leads to a planet frozen to the Equator ${ }^{4}$. Extremely large increases in carbon dioxide are required to terminate the glaciation and overcome the climate stability imposed by the high planetary albedo ${ }^{5}$. In Hyde et al.'s model ${ }^{1}$, with all the continents covered in ice, volcanic emissions without chemical weathering would cause atmospheric $\mathrm{CO}_{2}$ levels to rise. But with ice-free tropical oceans, even a modest rise in $\mathrm{CO}_{2}$ would cause the tropical glaciation to be short-lived. The exact duration would depend on the extent of chemical equilibration between sea water and calcium carbonate in the deep ocean, but it would be far less than the roughly 10 million years estimated from analysis of basin subsidence $^{3}$. It is also unclear how iron could accumulate in sea water to produce banded iron formations if tropical oceans were icefree. Moreover, the model of Hyde et al. predicts a progressive deglaciation from the Equator to the poles occurring at much lower $\mathrm{CO}_{2}$ concentrations, no higher than during the Cretaceous period.

Support for extreme increases in $\mathrm{CO}_{2}$ in the aftermath of the glaciations comes from cap carbonates, which are nearly ubiquitous features of Neoproterozoic glacial deposits. These carbonate rocks have distinctive features, including "knife-sharp" contacts with glacial deposits and unusual textures indicative of rapid precipitation on the sea floor ${ }^{6}$. The cap carbonates, which have been singled out as a climate paradox of Neo-

proterozoic geology ${ }^{7}$, are predicted by the snowball Earth hypothesis to be a consequence of intense carbonate and silicate weathering in the aftermath of the deglaciation. It is hard to reconcile the global occurrence of such a pulse of intense carbonate precipitation immediately after the termination of the ice ages with the progressive retreat of ice at moderate $\mathrm{CO}_{2}$ levels predicted by the Hyde et al. model.

Excitement over whether a semifrozen Earth might explain the geological observations stems from concern for the survival of eukaryotic life in such extreme and extended glaciations ${ }^{8}$. The critical feature is the survival of groups of photosynthetic algae that evolved before the glaciations. The survival of metazoans, as discussed by Hyde et al., is less problematic because such organisms (if they existed) could live wherever primary producers (photosynthetic or chemosynthetic) were still active. Photosynthetic algae could survive a series of glaciations in refugia near volcanic islands, such as Iceland and Hawaii, or beneath thin equatorial ice cover ${ }^{9}$. Evolution might well be stimulated by this prolonged genetic isolation, and by perturbations of biogeochemical cycles during the postglacial, ultra-greenhouse climate. This is consistent not merely with the survival of eukaryotic life, but also with the coincident radiation of metazoa and other groups ${ }^{8}$.

\section{Daniel P. Schrag, Paul F. Hoffman}

Department of Earth and Planetary Sciences,

Harvard University, 20 Oxford Street, Cambridge,

Massachusetts 02138, USA

e-mail: schrag@eps.harvard.edu

1. Hyde, W. T., Crowley, T. J., Baum, S. K. \& Peltier, R. Nature 405, 425-429 (2000).

2. Sohl, L. E., Christie-Blick, N. \& Kent, D. V. Geol. Soc. Am. Bull. 111, 1120-1139 (1999)

3. Hoffman, P. F., Kaufman, J. A., Halverson, G. P. \& Schrag, D. P. Science 281, 1342-1346 (1998).

4. Budyko, M. I. Tellus 21, 611-619 (1969).

5. Caldeira, K. \& Kasting, J. F. Nature 359, 226-228 (1992).

6. Kennedy, M. J. J. Sedim. Res. 66, 1050-1064 (1996).

7. Fairchild, I. J. in Sedimentology Review 1 (ed. Wright, V. P.) 1-16 (Blackwell, Oxford, 1993)

8. Runnegar, B. Nature 405, 403-404 (2000).

9. McKay, C. P. Geophys. Res. Lett. 27, 2153-2156 (2000).

Hyde et al. reply - We are not convinced that the data discussed by Schrag and Hoffman can be interpreted in only one way. With respect to the duration of glaciation, calculations $^{1}$ suggest that the open-water solution could have persisted up to $\mathrm{CO}_{2}$ levels of about four times those at present. With buffering from the reactive ocean carbonate reservoir, the time required for degassing to raise atmospheric concentrations to this level would be about $0.2-0.6$ million years (L. A. Derry, personal communication). As ice sheets would still discharge ground carbonate into the ocean, the buffering time would be extended. This timescale is consistent with range estimates derived from palaeomagnetic data ${ }^{2}$ and geochemical calculations ${ }^{3}$.

Our open-water results also agree with the environment of deposition of some glaciomarine sediments ${ }^{4}$. Iron is not a consistent feature of Neoproterozoic glacial sequences ${ }^{5}$. Meltwater from glacial calving could suppress water-column convection and decrease deep-sea oxygen; overturn ${ }^{6}$ could contribute to the low $\delta^{13} \mathrm{C}$ in postglacial sequences.

The idea that a modest $\mathrm{CO}_{2}$ increase would eliminate tropical glaciation in the open-water solution assumes a linear response, which is in contrast to many examples in the Pleistocene and the model used in our study ${ }^{1,7}$. Increases in $\mathrm{CO}_{2}$ produce virtually no meltback until a threshold level is reached ${ }^{1}$, whereupon a small increase causes rapid melting. Calculated ice-sheet retreat times of tens of thousands of years agree with sedimentological estimates ${ }^{8}$. Isostatic depression from the large ice sheets we describe could accommodate a thick layer of postglacial carbonate (only the thin bottom layer of which is cap rock in the strictest sense).

We are not as sanguine as Schrag and Hoffman about the ability of metazoans to survive under the extreme conditions of a hard snowball Earth. Whether life could survive on a few scattered volcanic islands is a matter of conjecture. A "thin-ice" scenario" is not consistent with results ${ }^{10}$ indicating that such regions have temperatures substantially colder than those estimated in ref. 9 (with implications for sea-ice thickness). Although evidence for life extends almost to the oldest rocks, three billion years transpired before the appearance of metazoans. This vast time interval suggests that the environmental tolerance of metazoans is much narrower than that of their simpler and hardier colleagues. If deep waters were anoxic, they could not survive on deep-sea chemosynthetic communities either, as these organisms still require free oxygen.

Future data may call for the reassessment of our open-water scenario, but we consider that the hard-snowball scenario is not yet proven. We believe that the open-water solution is much more favourable for the survival of metazoans, allowing their remote progeny to continue this discussion.

William T. Hyde, Thomas J. Crowley, Steven K. Baum, W. Richard Peltier*

Department of Oceanography, Texas A $\leftrightarrow M$ University, College Station, Texas 77843, USA

e-mail: hyde@rossby.tamu.edu

${ }^{*}$ Department of Physics, University of Toronto,

Toronto, Ontario M5S 1A7, Canada

1. Crowley, T. J., Hyde, W. T. \& Peltier, W. R. Geophys. Res. Lett. 28, 283-286 (2001).

Sohl, L. E. et al. Geol. Soc. Am. Bull. 111, 1120-1139 (1999).

3. Jacobsen, S. B. \& Kauffman, A. J. Chem. Geol. 161, 37-57 (1999)

4. Williams, G. E. Sedim. Geol. 106, 165-175 (1996).

5. Kennedy, M. J. et al. Geology 26, 1059-1063 (1998).

6. Knoll, A. et al. Science 273, 452-457 (1996)

7. Hyde, W. T. et al. Clim. Dynam. 15, 619-629 (1999).

8. Kennedy, M. J. \& Christie-Blick, N. in Soc. Sedim. Geol Conf. on Strata and Sequences on Shelves and Slopes (1998).

9. McKay, C. P. Geophys. Res. Lett. 27, 2153-2156 (2000).

10. Baum, S. K \& Crowley, T. J. Geophys. Res. Lett. (in the press). 